\title{
A Course in Mechatronics and Calling the Bluff on Active Learning
}

\author{
Brian Surgenor*, Kevin Firth* and Peter Wild** \\ *Department of Mechanical and Materials Engineering \\ Queen's University, Kingston, Ontario, K7L $3 N 6$ \\ surgenor@me.queensu.ca \\ **Department of Mechanical Engineering, University of Victoria \\ Victoria, British Columbia, V8W $3 P 6$ \\ pwild@uvic.ca
}

\begin{abstract}
When one talks about the elements needed for the next generation of engineering students, a list of the keywords typically includes the following: active learning, integrated learning, just in time instruction, theory versus practise, written and oral communication, multidisciplinary and interdisciplinary teams, lectures, tutorials, laboratories, workshops and design projects. An elective course in mechatronics engineering at Queen's University is put forward as an example of how one course can encompass all of these elements, and equally important, be able to promote the excitement and enthusiasm among the students for the subject in a manner that should be present in all engineering courses.
\end{abstract}

\section{Introduction}

This paper describes experience with an elective course in mechatronics. The course covers the application of electronics and microcontrollers to electro-mechanical systems. It employs a series of 'design, build and test' tasks involving a mobile robot that was designed and constructed at Queen's University. The "MechBOT" mobile robot has a large platform where sensors, actuators and associated circuits can be easily mounted and easily removed.

The majority of students taking the course are in mechanical engineering. There are some students from engineering physics and engineering mathematics. The objective is to expose students to elements of electrical and computing engineering, in much the same way that students are exposed to elements of manufacturing engineering in a machine shop course. The objective in an undergraduate machine shop course is not to turn students into machinists, but to sensitize them to the capabilities and limitations of machine tools. The mechatronics course does not cover the full range of computing, electrical and mechanical engineering topics that come under the heading of mechatronics engineering, but instead introduces students to sensor and actuator technologies and sensitizes them to mechatronic systems design issues.

Since the introduction of mobile robots in 1999 [1], the course has evolved as the instructors sought the appropriate level of structure and content, that would promote active learning, without requiring excessive time commitments on the part of the students and excessive resources from the department [2]. In terms of structure, the course is now organized to provide a combination of lectures, tutorials and laboratories at the beginning of the term, that culminate in a team project at the end of the term. The project requires a group of students to work in a cooperative fashion to create a team of mobile robots, a team that must perform a specified task. In the most recent presentation of the course, the task was to find and isolate multiple light sources that were setup to mimic a field of landmines.

\section{An Approach to Mechatronics}

MECH 452 Mechatronics Engineering is a fourth year elective course with an enrolment of roughly thirty students. The objective of the course is to 


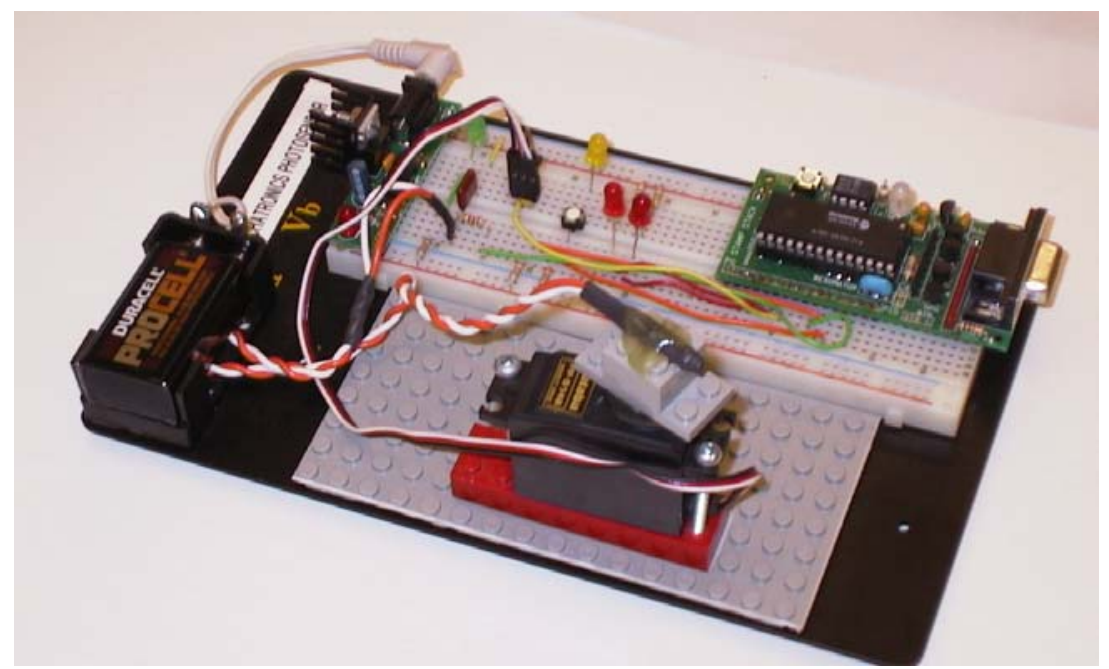

Figure 1: Prototyping board with microcontroller as configured for light sensing laboratory.

extend a student's working knowledge of engineering to include applied electronics and microcontrollers. The course is designed around a series of laboratories that involve a prototyping board and a mobile robot. The BASIC Stamp SX

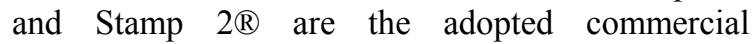
microcontrollers (Figure 1). The "MechBOT" mobile robot was designed in-house and has an easy to use platform on which sensors, actuators and associated circuits are mounted (Figure 2). The commercially available educational mobile robots in 1999 did not provide enough space to accommodate the range of sensors and actuators that were originally envisioned for the course [3].
It is acknowledged that just as mechatronics courses are commonly laboratory-based, the mobile robot has been effectively adopted as a standard educational tool [4]. Although mobile robots have regularly been used as a tool in electrical engineering programs, mechatronics has provided an opportunity to introduce such devices to nonelectrical, and in particular, mechanical engineering students [5].

A series of eight laboratories are used to introduce the students to the technology. They alternate between the applying the technology to the prototyping board in one week, and then applying

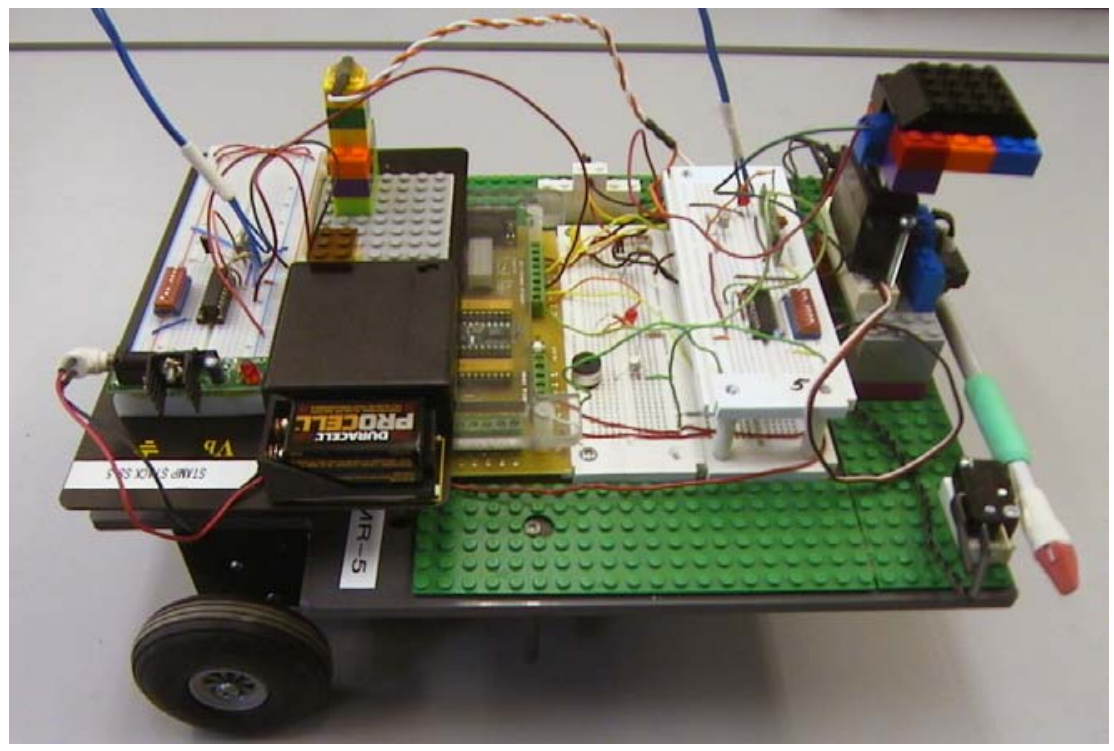

Figure 2: MechBOT mobile robot as configured for the team design project. 


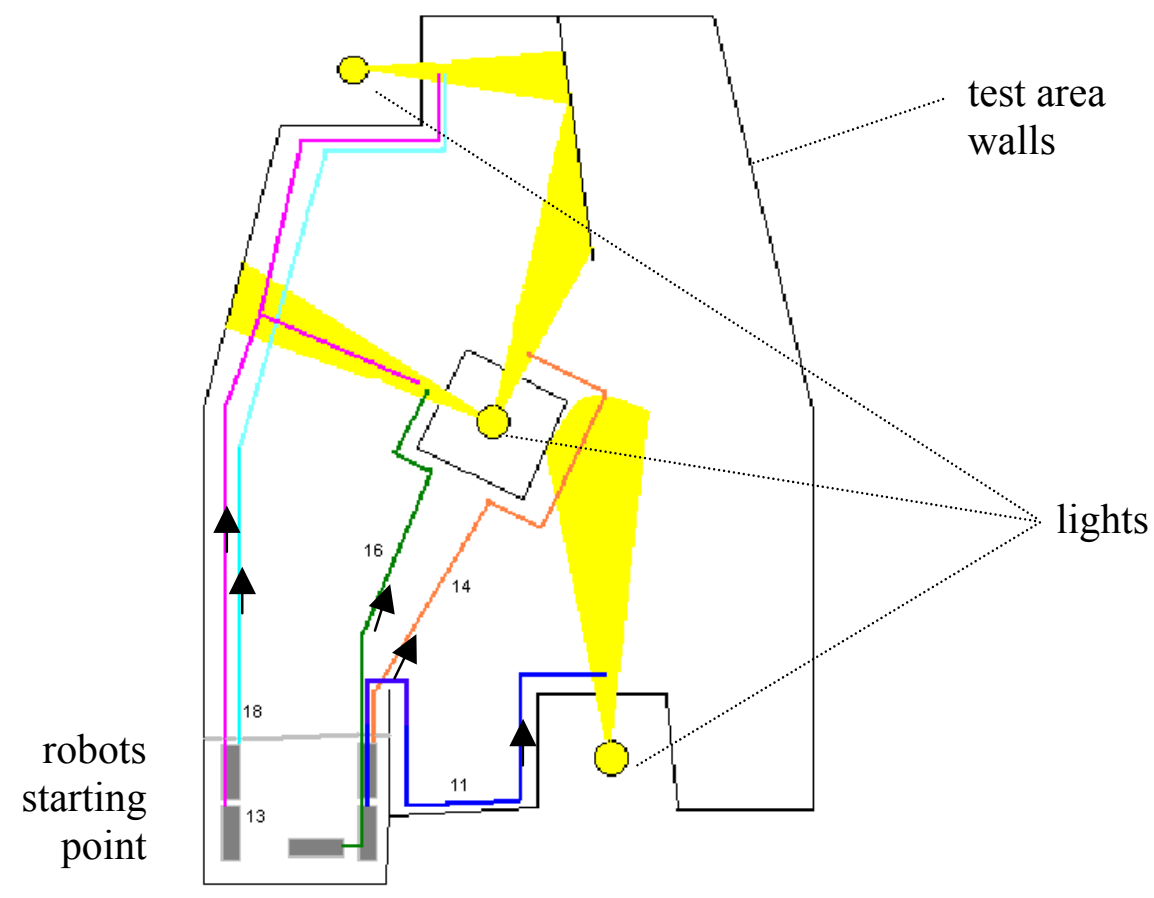

Figure 3: One group's search strategy for the team design project.

the same technology to the mobile robot in the following week:

- $\quad$ Lab \#1 and Lab \#2, navigation by contact sensing (limit switches)

- Lab \#3 and Lab \#4, navigation by light sensing (photoresistors), with Lab \#3 illustrated in Figure 1 (photoresistor mounted on servomotor, as controlled by microcontroller)

- Lab \#5 and Lab \#6, navigation by ranging (infrared sensor), with Lab \#6 illustrated in Figure 5 (class discussion shown, robot required to track the centerline)

- Lab \#7 and Lab \#8, navigation by RF (wireless communication)

These laboratories are conventional in that they are highly structured. A handout details the procedure and every group works with the same hardware. Variation between groups arises from the programming and in the handling of the sensors, actuators and associated circuits.

For the laboratories, students work in pairs, and this occupies the first eight weeks of the course. In the final four weeks of the course, the experience and knowledge gained in the laboratories is applied to a team design project. In this case, "team" means eight students working together with five robots. The most recent project involves a problem that mimicks a team of autonomous robots trying to find and isolate multiple landmines (represented as lights).

The most recent version of the project task is illustrated in Figure 3, which shows a plan view of the test area. Three floor mounted lights are hidden behind three blinds. There are four openings in the blinds (corresponding to the four "beams" of light shown in the figure). Five robots were tasked to find and cover the four openings. The numbers 11 , $13,14,16$ and 18 identify the group number of each robot. Each team gives an oral presentation on their design strategy. Figure 3 is taken from one team's presentation and it shows the intended path of the five robots. The common search strategy was to assign a light to each robot. The fifth robot was redundant. In Figure 3, one sees that robot \#13 and \#18 were assigned the same light. This particular task was chosen as it makes use of all of the technology learned in the first half of the course, and it mimics a very real and very significant application of multiple autonomous mobile robots (landmine detection and isolation). The students learn very quickly that one of the biggest problems is that of 


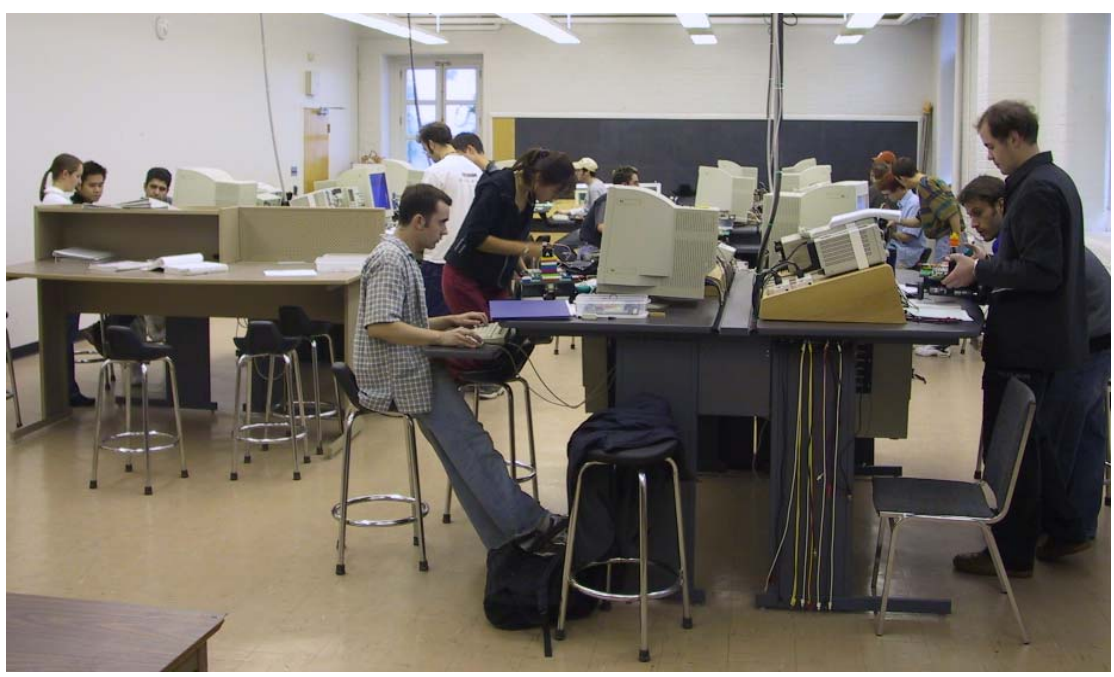

Figure 4: Mechatronics lab, view showing individual workstations.

spurious and faulty sensor readings. The bulk of the design time is spent addressing this problem, typically by the application of redundant sensors in combination with innovative programming.

\section{The Mobile Robot}

Having a mobile robot that fits the needs of the course has been a key element in the success of the course. The ability to add sensors and actuators to the MechBOT mobile robot platform by including a Lego ${ }^{\circledR}$ mat on the deck is important in a number of ways (see Figure 2).

1. As the course evolved, both the tasks and the sensors have changed. The sensors are mounted on Lego ${ }^{\circledR}$ bricks so changes are simply made.
2. In the early labs only the required equipment is present.

3. When a component fails it is easily replaced by the student from a set of spares.

4. In the advanced tasks, sensor location and orientation are part of the design strategy and can influence the effectiveness and reliability of the design.

5. There is more involvement in the wiring and calibrating of the sensors than with a commercial kit that is completely hardwired.

6. In labs that introduce new sensors with the prototype board, which also has a Lego ${ }^{\circledR}$ mat, the entire focus is on the new sensor without concern for robot operation

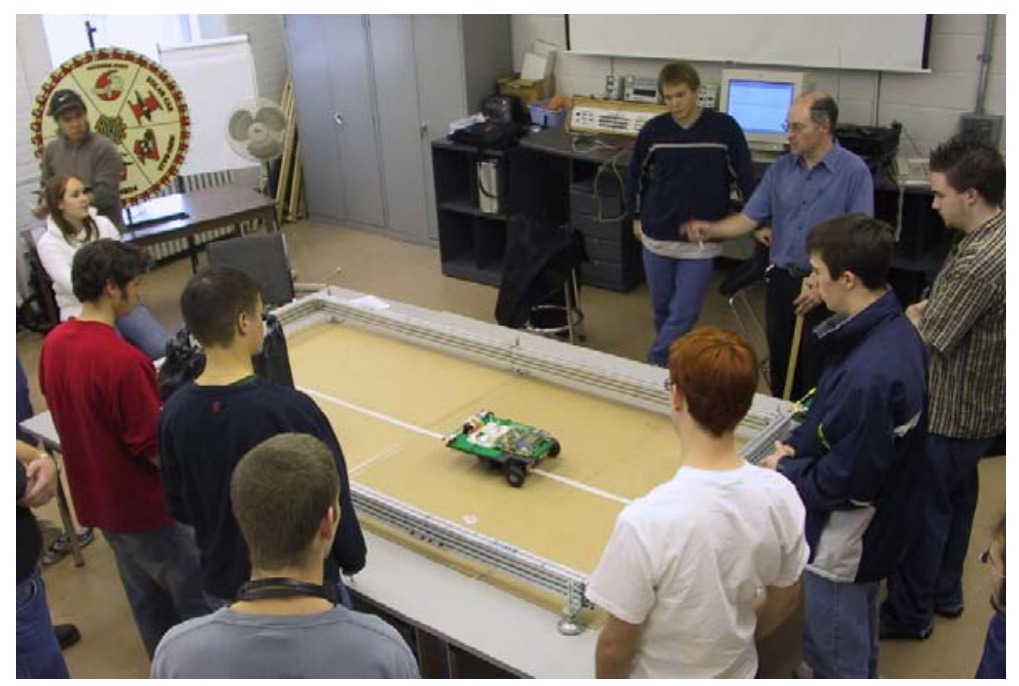

Figure 5: Mechatronics lab, view showing demonstration and tutorial facilities. 
7. There is a heightened sense of building for the students and an opportunity for artistic as well as technical creativity.

It was found that the basic robot platform could be built at a cost less than that of a comparable commercial mobile robot (for example Lego $\AA$ Mindstorms). In addition, the Basic Stamp2 ${ }^{\circledR}$ had more input/output than the Lego ${ }^{\circledR}$ processor, and it was good not to be constrained by Lego ${ }^{\circledR}$ sensors. Furthermore, while the Lego ${ }^{\circ}$ instant building feature was advantageous, the blocks are not ideal when it comes to creating rugged structures. With the PVC panel based platform, mechanical failures are limited to the sensor support structures built by the students.

\section{Course Workspace}

Suitable workspace has been a second key element in contributing to the success of the course. In our case we are fortunate to have a room of ten workstations (plus one instructor workstation) each equipped with a computer, power supply, oscilloscope and multimeter (Figure 4). There is storage space for equipment, open floor space for demonstrations and a data computer projector for lecture based tutorials (Figure 5).

Accessibility to the workspace is also an important issue. Students are given keys allowing them 24 hour access to the laboratory. More importantly, they are the only users of the space. Thus, the students (and the instructors) have the luxury of a dedicated workspace, in much the same way that external competition design teams have dedicated workspace. At a time when every university is short of space due to expanding enrolment, this is viewed as highly inefficient use of space. However, allowing students to come in at any time to work on their project, and the fact that laboratories do not have to be torn down at the end of every laboratory period, has led to very effective learning.

\section{Organization for Active Learning}

The active learning component attracts a group of students that is enthusiastic about the hands-on nature of the course. However, this enthusiasm can become a problem when the hours spent testing and troubleshooting begin to use up time required for other courses. Steps that can be taken toward achieving a sensible balance between independent study and limiting the hours spent on the course are as follows:
1. A tight coupling between lecture and laboratory activity.

2. Arranging a preliminary task that is to be completed in the tutorial in order to avoid time wasted in cases where basic errors are being made at the outset.

3. Solid support during the tutorial and the laboratories by people who know the problems and how to solve them.

4. Back up robots and sensor sets.

5. Attendance at laboratories and tutorials is mandatory.

6. Prototyping boards and robots that are prebuilt for the first day with the basic components laid out in the same manner on every robot; making for easier troubleshooting.

7. Start with prepared sample code for the first task.

8. Have the class gather around the test area and demonstrate successful example runs at the beginning of the laboratory (except in the final design project) as a method of being clear about the target, generating relevant questions right away, and giving the students confidence that the task can be done (see Figure 5).

9. Provide component data sheets as hardcopy in the laboratory and on course website.

10. Provide a clear handout with the task and the marking scheme clearly identified.

11. Package the material as one week, or later as two week, sessions that include a tutorial and a demonstration prior to the actual laboratory.

12. Walk around from group to group during laboratories to keep in touch with progress and do not let a group spend excessive time on a simple troubleshooting problem.

13. Have a large whiteboard on hand and post common problems and answers to common questions as they arise during the course of the laboratory.

Ideally these steps lead to a balance where students are free to work hard at solving problems on their own, yet will not go overboard such that hours in the laboratory detract from the rest of their course work. The importance of Point 8 (prelab demos) cannot be overstated. This is key not only for the actual demonstration, but it also serves as a planning tool. Only by actually doing the task with the tools at hand can an instructor prepare the appropriate 
instructions and be aware of most (or at least some) of the problems the students will face.

It is helpful to discuss with the students at the beginning of the course how they may find these labs a bit different from other experiences. When the instructors are introducing a task into the course for the first time there may be problems and solutions that are not identified in the lab handout. The students need to understand up front that the objective is to create a challenging learning environment and that may require adjustments to the task during implementation. These adjustments should be kept to a minimum and when they are made, clearly communicated to everyone.

The prevalence of competitive robotics is an indicator that competition attracts the attention of enthusiastic teams and spectators. In the MECH 452 environment though, there has been a consistent effort made to foster a cooperative, supportive learning atmosphere where people share what they have learned. Combative tasks are avoided. The students compete against the task rather than against each other and when someone does well, everybody claps.

\section{Course Assessment}

Student comments about the course in its current form have been universally positive, a selection of which are given below:

- $\quad$ "it's the best class I've ever taken, I like the practical application of things"

- $\quad$ this course is awesome, I (think) everyone loves it"

- $\quad$ "I liked the hands-on experience, it made learning material easier and more fun"

- "good setup learning how to use components first (alone) and then on the robot"

In Fall of 2003, the course was ranked $1^{\text {st }}$ out of the 12 electives then offered by the Department, as measured by the University Survey of Student Assessment of Teaching, a formal course evaluation that is conducted for all courses by the university. The course scored 4.8 on a scale of 5 in response to the question "overall, this is an excellent course", with the Department mean at 3.7 (standard deviation of 0.36 ), where 5 = "strongly agree". Evaluations from the Fall of 2004 are equally positive.
Possibly the most telling feedback from students is one of the most common requests: "Could you please offer Mechatronics II next term ?"

\section{Lessons Learned}

As has already been mentioned, the most worrisome aspect of the course was the required time commitment from the students. Although students were overwhelming in support of the course, they were very much aware of the fact that their other elective courses were less demanding in terms of time and effort. Although the course is still demanding, it is believed that the current organization is optimal. To repeat, the course starts with (small) group structured laboratories and ends with a (large) team open design project. The laboratories are carefully organized to introduce the technology needed in the design project as well as expose the students to implementation problems with individual elements. This reduced the frustration factor when it comes to the systems integration problem presented by the design project. The frustration factor is also minimized by introducing new sensor technology at the protoboard level before applying the technology at the level of the mobile robot.

Although the design of the mobile robot together with the nature of the adopted laboratory workspace are considered the two key factors, many elements make for a successful course. The following elements also warrant repeating:

- Small class (30 total or 15 pairs of students for the labs)

- Two faculty members (who monitor performance in the tasks on a lab by lab basis, and provide updates accordingly, in hopes of staying one step ahead of the students)

- Structured small group laboratories are followed by unstructured team projects

- Microcontroller language with a fast learning curve (PBASIC, not C)

- The cooperative team project avoids time as a performance measure

- Active learning approach to the subject (hands-on tasks with group tutorials and demos)

- Spare robots and sensors on hand 


\section{Calling the Bluff with Active Learning}

The mechatronics course has been very well received by students, but it has also developed a reputation as being "too demanding". This is a reflection of the fact that it is an interdisciplinary course with a hands-on approach to active learning. Active learning requires greater effort on the part of everybody. Furthermore, the requirements for space, equipment and technicians far exceed the requirements of conventional courses.

Active learning is said to be the key to successful education. To paraphrase Piaget “ $\ldots$ in order for a student to understand something, she must construct it herself, she must re-invent it." Students who are actively engaged in the learning process have a better chance of truly mastering the material [6]. The best way to engage students is to create an exciting active learning environment. In engineering, a workshop and design project based course should lend itself naturally to the creation of an active learning environment. Engineering is a hands-on profession. However, one cannot overstate the costly nature of active learning, in terms of both physical and human resources. Although the mechatronics course has been put forward as a success story, it seems appropriate to use this experience to "call the bluff" of those who advocate widespread application of active learning and related education initiatives, and yet fail to acknowledge the cost in terms of financial, physical and human resources [7]. Most agree that in principle, engineering education should embrace active learning. But at what cost?

\section{Conclusion}

MECH 452 is not a course in mobile robots, in the sense that the objective of the course is not to train students such that they can design mobile robots upon graduation. On the other hand, it is the "fun" nature of the mobile robot that contributes to the success of the course. The stated objective of the course is to extend a student's working knowledge of engineering to include applied electronics and microcontrollers, as well as to sensitize each student to the issues that impact on the design of mechatronic systems. MECH 452 is also an interdisciplinary course with a hands-on approach to active learning. Active learning requires greater effort on the part of both instructors and students. And to quote a MECH 452 student:

"Take this course if you want to learn, don't take this course if you aren't willing to work for it."

One must remember that this is an elective course, with a small dedicated group of students who wanted to learn about mechatronics, who on the whole are fully aware of the commitment that active learning requires. The implication is that the course might not be as successful as a core course with a large class ( $>100$ students).

\section{References}

1. Wild, P.M. and Surgenor, B.W., "An Innovative Mechatronics Course for a Traditional Mechanical Engineering Curriculum, ASEE Annual Conference Proceedings, Session 2566, Charlotte, North Carolina, 1999.

2. Wild, P.M., Surgenor, B.W. and Zak, G., "The Mechatronics Laboratory Experience", Journal of Mechatronics, Vol. 12, 2002, pp. 207-215.

3. Firth, K, Surgenor, B.W. and Wild, P.M., "A Task Based Approach to Mechatronics Systems Education", Proceedings ASME Conference on Engineering Systems, Design and Analysis, ESDA2004-58475, Manchester, UK, 2004.

4. Weinberg, J.G. and $\mathrm{Yu}, \mathrm{X}$., "Robotics in Education: Low-Cost Platforms for Teaching Integrated Systems", IEEE Robotics \& Automation, June, 2003, pp. 4-6.

5. Greenwald, L. and Kopena, J., "Mobile Robot Labs", IEEE Robotics \& Automation Magazine, June, 2003, pp. 25-32.

6. Goff, R.M., "The Art of Creating an Active Learning Environment", ASEE Annual Conference Proceedings, Session 2793, Montreal, Canada, 2002

7. Wood, J.J and Wood, K.L. "The Tinkerer's Pendulum for Machine Design Education: Creating a Basic Hands-On Environment with Mechanical Breadboards", ASEE Annual Conference Proceedings, Session 2566, St. Louis, U.S.A., 2000. 